\title{
Evaluation of studies of health economics
}

\section{Clinical scenario}

A rural hospital hires a new infection control professional, EL, who has just received her master's degree and trained in infection control departments that were up to date on the best evidence. EL reviews the infection control policies and learns that traditional central line catheters are used. Where she trained, a new, more expensive, antiseptic catheter was used. The new catheter is impregnated with chlorhexidine and silver sulfadiazine and costs $\$ 25$ more than the traditional catheter.

Because the new catheter is designed to reduce the incidence of hospital associated infections, particularly blood stream infections that are catheter related, EL recommends that the hospital begin using it in place of the traditional central line catheter. However, hospital administration and the purchasing department question the value of this new, more expensive, antiseptic impregnated catheter. Issues related to both cost and the possibility of improved outcomes are discussed at a meeting with intensive care nurses, physicians, and representatives from hospital administration and the purchasing department. Specifically, the questions are: (1) is the antiseptic impregnated catheter economically efficient? In other words, are the additional costs of the catheter offset by potential cost savings in reduced number of infections, which will affect length of stay? (2) Is the antiseptic impregnated catheter more cost effective when used in certain types of patients (eg, patients at high risk of catheter related infections, such as immunosuppressed patients)? An interdisciplinary team is asked to conduct a literature search and make an evidence-based recommendation.

\section{Introduction}

As healthcare technology continues to expand, the cost of using all effective clinical services exceeds available resources. Because of the scarcity of resources, decisions regarding the implementation of new services frequently need to be based on economic analysis. Economic analysis is a set of formal, quantitative methods

Table 1 Questions to help critically appraise economic evidence

Are the results of this economic evaluation valid?

\begin{tabular}{|c|c|}
\hline 2. & Are the alternative courses of action appropriate and well defined? \\
\hline 3. & $\begin{array}{l}\text { Is the perspective of the analysis stated, and are appropriate costs } \\
\text { considered? }\end{array}$ \\
\hline 4. & $\begin{array}{l}\text { If cost utility analysis methods are used, are the utilities (patient } \\
\text { preferences) reasonable? }\end{array}$ \\
\hline 5. & $\begin{array}{l}\text { Are the events used comprehensive, and are the probabilities of } \\
\text { events derived from credible sources? }\end{array}$ \\
\hline 6. & Are data on costs and outcomes appropriately discounted? \\
\hline \multirow[t]{2}{*}{7.} & Is uncertainty in the data adequately addressed? \\
\hline & What are the results of this economic analysis? \\
\hline 1. & $\begin{array}{l}\text { How do the resulting costs or costs/unit of health gained compare } \\
\text { with other interventions? }\end{array}$ \\
\hline \multirow[t]{2}{*}{2.} & $\begin{array}{l}\text { Are the conclusions likely to change with sensible changes in } \\
\text { costs and outcomes? }\end{array}$ \\
\hline & Will the results help me in caring for my patients? \\
\hline 1. & Do the costs in the report apply in my own setting? \\
\hline 2. & $\begin{array}{l}\text { Will the intervention (or new model of care) be effective in my } \\
\text { setting? }\end{array}$ \\
\hline
\end{tabular}

used to compare 2 or more treatments, programmes, or strategies with respect to their use of resources and their expected outcomes. ${ }^{1}$ Economic evidence seeks to inform resource allocation decisions at different levels, including institutions (eg, hospitals) and regional or national governments. Unfortunately, not all economic evidence is of high quality. To identify scientifically sound evidence that can inform nursing related resource allocation decisions, nurses need to evaluate the research by answering the questions outlined in Table 1 . These questions will be discussed and illustrated with examples of interest to nurses; then, the clinical scenario will be addressed and a published economic evaluation will be critiqued to further illustrate these points.

\section{Are the results of this economic evaluation valid?}

The number of published economic evaluations is growing. ${ }^{2}$ However, many experts in the field have questioned the methodological rigour of these evaluations. ${ }^{3}{ }^{4}$ Therefore, it is important for nurses to be able to assess the validity of the methods used in these economic studies in order to determine which findings they will apply to their setting.

All rigorous economic evaluations consider the opportunity cost; that is, the value of the benefits foregone in alternative uses when a resource is used for a given purpose. ${ }^{5}$ For example, the opportunity cost to a municipality's health department of funding a community health screening programme for the elderly may be the foregone benefits of not being able to fund a prenatal programme for at risk pregnant women. In addition, economic evaluations should consider the extra (ie, incremental) benefit that would be gained for the extra (ie, incremental) cost. A classic example illustrating incremental cost and effectiveness is the sixth stool guaiac test used to screen for colorectal cancer in people over 40 years of age. In the US, the average cost per case of cancer detected using $\leq 5$ tests has been calculated to be US $\$ 2541$, but the incremental cost of the sixth test was estimated to range between $\$ 47$ and $\$ 127$ million. ${ }^{6}$ This is because the probability of detecting an additional case of cancer (the incremental effectiveness) is so low that millions of dollars (the incremental costs) would be spent before identifying one more person with cancer.

\section{IS THE APPROPRIATE ECONOMIC EVALUATION METHOD USED?}

5 different analytic tools are commonly used to assess the economic effects of new and established healthcare interventions (Table 2). Each method will be discussed below. The costs should be measured the same in all analyses, but the methods differ in how effects or outcomes are measured.

\section{Cost-minimisation analysis (CMA)}

In a true CMA, only costs are evaluated. The central assumption is that the outcomes of the alternative interventions or strategies are considered equivalent, and so the goal is to find the least expensive way of achieving the outcomes. ${ }^{1}$ For example, a cost minimisation study was used to evaluate the savings from early hospital discharge of patients with osteomyelitis followed up by outpatient antibiotic treatment when compared with 
conventional inpatient treatment. When total costs per patient were compared, the early discharge programme resulted in a savings of US $\$ 510$ per patient. ${ }^{7}$ Because CMA assumes that clinical outcomes are the same, the evaluation is essentially a search for the least costly alternative - the minimal cost strategy (in this case, early hospital discharge). However, the circumstances under which CMA is an appropriate method of analysis are limited because the technique is only appropriate when outcomes have been rigorously shown to be equivalent.

\section{Cost consequence analysis (CCA)}

In a CCA, the consequences of 2 or more alternatives are measured in addition to the costs. In a CCA, the consequences of each alternative are listed, and decision makers form their own opinions about the relative importance of the findings. For example, researchers evaluated the outcomes and costs of a modified therapeutic community intervention for homeless mentally ill people who abused chemicals versus treatment as usual. ${ }^{8}$ The incremental costs of the therapeutic community compared with treatment as usual were computed, and the outcomes of each model of care were listed. Readers were left to draw conclusions about the choice of intervention based on costs and outcomes.

\section{Cost effectiveness analysis (CEA)}

In CEA, the health outcomes of each alternative must be reported using the same units, such as life years gained or migraine headaches prevented or $\mathrm{mm} \mathrm{Hg}$ of diastolic blood pressure lowered. Additionally, costs and effects are summarised in a cost effectiveness ratio, which is calculated using the following formula:

$$
\left(\mathrm{C}_{1}-\mathrm{C}_{2}\right) /\left(\mathrm{E}_{1}-\mathrm{E}_{2}\right)
$$

where $\mathrm{C}_{1}=$ the cost of the new intervention, $\mathrm{C}_{2}=$ the cost of the comparator, $\mathrm{E}_{1}=$ the effect of the new intervention, and $\mathrm{E}_{2}=$ the effect of the comparator. With CEA, analysts often use a decision analytic approach (ie, a complex mathematical modelling technique) that captures the long term costs and effectiveness.

A few examples of CEA can be found in the nursing literature, such as the cost effectiveness of neonatal nurse practitioners and the cost effectiveness of a free standing birth centre. ${ }^{910} \mathrm{In}$ CEAs that use a standard unit for analysis, such as life years gained, the advantage is that comparisons can be made across groups or settings by using league tables. Results of separate analyses from various healthcare settings can be compared, at least in theory, across patient populations. ${ }^{11}$

Cost utility analysis (CUA)

CUA is a special type of CEA that uses a standardised measurement and includes measures for both the quantity and quality of

Table 25 types of economic evaluations

\begin{tabular}{cl}
$\begin{array}{c}\text { Economic evaluation } \\
\begin{array}{c}\text { Cost minimisation } \\
\text { analysis (CMA) }\end{array}\end{array}$ & $\begin{array}{l}\text { An analytic tool for estimating the costs of } \\
\text { strategies when the effects are equal. }\end{array}$ \\
\hline $\begin{array}{c}\text { Cost consequence } \\
\text { analysis (CCA) }\end{array}$ & $\begin{array}{l}\text { An analytic tool in which incremental costs and } \\
\text { consequences are listed without any attempt to } \\
\text { aggregate them. }\end{array}$ \\
\hline $\begin{array}{c}\text { Cost effectiveness } \\
\text { analysis (CEA) }\end{array}$ & $\begin{array}{l}\text { An analytic tool in which incremental costs and } \\
\text { effects are combined into a ratio, and effects are } \\
\text { measured in a common natural unit. }\end{array}$ \\
\hline $\begin{array}{c}\text { Cost utility analysis } \\
\text { (CUA) }\end{array}$ & $\begin{array}{l}\text { A specific form of CEA in which effects are } \\
\text { measured in costs per quality adjusted life years } \\
\text { (QALY) gained. }\end{array}$ \\
\hline $\begin{array}{c}\text { Cost benefit analysis } \\
\text { (CBA) }\end{array}$ & $\begin{array}{l}\text { An analytic tool for estimating the net social } \\
\text { benefit of a strategy in which both costs and } \\
\text { effects are measured in currency. }\end{array}$ \\
\hline
\end{tabular}

life. Outcome measures that consider both quality and quantity of life include disability adjusted life years (DALYS), healthy year equivalents (HYEs), and quality adjusted life years (QALYS), which is the most common. The QALY combines patient longevity and individuals' preferences about different levels of health related quality of life into a single measure, which, in principle, has meaning across all areas of health service activity. ${ }^{12}$ It is a unit of measure for survival that accounts for the effects of suboptimal health status and the resulting limitations in quality of life. It is usually measured on a scale of 0 (representing death) to 1 (representing full health). Quality adjustment involves placing a lower value on time spent with impaired physical and emotional function than time spent in full health: the greater the impairment, the lower the value of a particular health state. It is not realistic to expect an individual to sustain the same quality of life over time; rather, people move in and out of health states (eg, a person has a stroke and then recovers). Individual QALYs are calculated by multiplying the time spent in each health state by the preference for that health state. These are then summed to arrive at an overall QALY. In a classic study, Boyle et al used a utility measure to calculate that treating critically ill infants weighing 1000-1499 $\mathrm{g}$ at birth cost CN $\$ 3200$ per QALY gained, whereas treating infants with birth weights of 500-999 g cost $\$ 22400$ per QALY gained. ${ }^{13}$

\section{Cost benefit analysis (CBA)}

In CBA, outcomes are measured according to a monetary unit. A single currency figure, representing benefits minus costs, is calculated. The challenge of this approach is that many healthcare situations are difficult to quantify financially and require a value judgment. Furthermore, there are ethical concerns surrounding the assignment of a monetary amount to the value of human life.$^{14}$ Because of these issues, the use of CEA has been more prevalent in the healthcare literature than CBA. ${ }^{3}$ An advantage of using CBA in health care is that the results may be compared to other areas of government investment (eg, school education or transportation safety).

\section{ARE THE ALTERNATIVE COURSES OF ACTION}

APPROPRIATE AND WELL DEFINED?

In determining the validity of any economic evaluation, you must decide if the alternative ways of providing care being evaluated in the study are appropriate and well defined. For example, researchers did a study to determine if a transprofessional model of home health care could produce savings in service delivery costs compared with usual home care for patients with AIDS who were terminally ill. ${ }^{15}$ The researchers found no improvements in clinical outcomes, but did find an 8\% reduction in delivery costs for patients who received transprofessional care management. Of key importance was that the new intervention (ie, transprofessional care management) was clearly articulated and appropriately compared with current usual care.

In an economic analysis, it is not necessary to view an intervention as "all or nothing". The costs and consequences of treatment are likely to vary depending on patients' levels of risk. The greater a patient's risk, the lower the cost per unit of benefit. Therefore, subgroups with different levels of risk need to be identified, and costs and consequences need to be provided separately for each subgroup. Certain interventions may only be economically efficient in high risk individuals.

IS THE PERSPECTIVE OF THE ANALYSIS STATED, AND ARE APPROPRIATE COSTS CONSIDERED?

Table 3 lists some of the resources frequently measured in economic evaluations. When assessing costs, 2 components drive 
the measurement: (1) the perspective of the analysis and whether the appropriate resources were considered for that perspective; and (2) how the value (or cost) of the resources was determined.

\section{The perspective of the analysis}

Central to any economic evaluation is the issue of whose costs and benefits are to be considered. Costs and benefits might be seen differently from the points of view of society, the patient, the payer, or the provider. The appropriate resources to consider vary depending on the perspective from which the analysis is done and the question being asked. ${ }^{16}{ }^{17}$ For example, an intensive care unit (ICU) manager may only be interested in costs incurred while patients are in the ICU. Therefore, only resources consumed by the intervention or the alternatives and the length of ICU stay may be of interest. However, a hospital administrator would be interested in the resources used during the entire hospital stay. Often, resources related to the intervention itself and those associated with net downstream healthcare utilisation are of interest. For example, an insurer or national healthcare service will be interested in the direct costs associated with the initial hospital stays, including resources related to supplies and staffing as well as downstream resource utilisation, such as hospital readmissions, outpatient visits, and other treatments associated with the diagnosis of bloodstream infection and other related diseases (eg, sepsis). Furthermore, when conducting an analysis from a societal perspective, costs and effects are included regardless of who accrues them. Therefore, non-healthcare resources are included.

Ideally, all economic evaluations should have a societal perspective. However, because of the difficulty of assessing societal perspectives as well as the specific concerns of decision makers, analyses are often done using a more narrow perspective. The danger in using a narrow perspective is that costs may simply be shifted. For example, the cost savings related to a shorter hospital stay may be shifted to outpatient visits and to the family in terms of extra caregiver burden.

\section{Valuing resources or costs}

Analysts vary in how they value resources. ${ }^{18}$ In healthcare environments, charges generally do not equal true costs. Third party payers negotiate payment for services rendered based on the cost of the service and an agreed upon profit margin. This occurs in both for profit and not for profit institutions. In order for healthcare institutions to generate more revenue, fee for service customers are often asked to pay full charges (ie, a higher rate of pay). This is called institutional "cost shifting." Therefore, in the US, many analysts use cost to charge ratios (CCRs), which are calculated by dividing the total costs in a given cost centre by the total charges for the same resource. CCRs are recognised as a gross adjustment to charges. They are better than using charges alone, but not as accurate as cost accounting systems.

Additionally, because 1 dollar (or 1 pound) in 1980 does not have the same purchasing power as a current dollar (or pound), the costs from different years must be calculated and placed into

Table 3 Resources frequently measured in economic evaluations of health care

\begin{tabular}{ll} 
Direct health care & Direct non-health care \\
Intervention & Transportation \\
\hline Admission to hospital & Family and caregiver time \\
\hline Outpatient visits & Social services \\
\hline Long term care & Patient productivity \\
\hline Other health care & \\
\hline Patient time spent receiving care & \\
\hline
\end{tabular}

a standard year format. Standardisation of all costs to the same currency and year is essential.

IF CUA METHODS ARE USED, ARE THE UTILITIES (PATIENT PREFERENCES) REASONABLE?

Methods for eliciting utilities (patient preferences) vary and are the focus of a unique body of science and research. ${ }^{19-22}$ However, a systematic review found that many similar health states have been valued quite differently (ie, mild angina had a low value of 0.7 and a high value of 0.95 ) and these assigned values were often based on the opinions of the authors rather than rigorous assessment of patient or community based preferences. ${ }^{23}$ Therefore, careful attention is warranted when assessing preference weight scores and how they were derived. Increasingly, utilities are being collected for various health states. ${ }^{24} 25$

\section{ARE THE EVENTS USED COMPREHENSIVE, AND ARE THE} PROBABILITIES OF EVENTS DERIVED FROM CREDIBLE SOURCES?

For each alternative (eg, intervention) considered, there are probabilities of events occurring (eg, desired outcomes or side effects). Decision makers need to assess if the events included are comprehensive, drawing on their own clinical expertise or collaborating with clinical experts. Additionally, the reliability of the evidence should be considered. Some economic evaluations are done in conjunction with randomised controlled trials (RCTs), whereas others are based on existing evidence from published RCTs and meta-analyses. Because the economic evaluation may include modelling of long term outcomes, analysts often identify probabilities of these events from various sources.

\section{ARE DATA ON COSTS AND OUTCOMES APPROPRIATELY} DISCOUNTED?

After all costs and benefits have been calculated, future costs and benefits are discounted to present value. Discounting reflects the principles of time preference and opportunity costs. Time preference suggests that people place greater value on something they have today than on something they will have in the future. Interest rates reflect these same principles - if you forego the opportunity of buying something today and invest the money, you will enjoy a higher rate of return in the future. Therefore, future costs and benefits are discounted to present value using the following formula:

\section{$\mathrm{F} /(1+\mathrm{r})^{\mathrm{n}}$}

where $\mathrm{F}=$ the future value, $\mathrm{r}=$ the discount rate, and $\mathrm{n}=$ the number of years. ${ }^{25}$ Currently, most experts recommend using a $3 \%$ discount rate to discount both costs and effects. ${ }^{26}$

IS UNCERTAINTY IN THE DATA ADEQUATELY ADDRESSED? Decision making in health care is inevitably done in a context of uncertainty. Sensitivity analysis and cost effectiveness acceptability curves determine the degree to which this uncertainty could influence conclusions about the economic impact of clinical decisions. Through the use of these techniques, results are calculated separately, varying uncertain estimates of risks, benefits, and values over a reasonable set of parameters. ${ }^{26}{ }^{27}$ This allows analysts to determine how different the results of the analysis might be given the different possible estimates. For example, in a univariate sensitivity analysis, a parameter such as a utility (preference) weight is varied and indicates the degree of influence the particular value has on the outcome of the entire analysis. Although univariate sensitivity analyses are insightful, looking at only one variable is usually inadequate. Multivariate 
sensitivity analysis and cost effectiveness acceptability curves examine multiple sources of uncertainty at one time and may generate a more accurate estimate of cost effectiveness under varying conditions and better inform decision makers. Assessing uncertainty is an important element of a sound economic evaluation.

\section{What are the results of this economic analysis?}

Once it has been determined that the economic analysis is valid, the results of the analysis can be examined. To do this, we must consider whether the intervention will provide a benefit at an acceptable cost. For example, if a CMA was done, we should consider if the difference in cost is large enough to warrant switching to the new intervention. If CUA was done, we should consider how the costs/QALY compare with other interventions.

\section{HOW DO THE RESULTING COSTS OR COSTS/UNIT OF} HEALTH GAINED COMPARE WITH OTHER INTERVENTIONS? Given finite resources, it is often necessary to make choices among interventions. League tables list cost effectiveness results from several different studies and, in theory, allow readers to compare the cost effectiveness of different interventions. Several such tables are available in the published literature, but, because of the wide variation in methods used in the original studies, these tables may be misleading if taken at face value. ${ }^{28}$ In one league table, all results were standardised to a common currency and attempts were made to ensure correct calculation of cost effectiveness ratios to improve comparability of the results across analyses. ${ }^{29}$ However, the assumptions made in the individual analyses, such as the choice of comparator, were not judged.

\section{ARE THE CONCLUSIONS LIKELY TO CHANGE WITH}

SENSIBLE CHANGES IN COSTS AND OUTCOMES?

Readers of economic evaluations often wish to judge the robustness of the results given different assumptions or scenarios. For example, Meenan et al found that an in-hospital smoking cessation counselling and education programme was more effective than current practice for helping patients to stop smoking at 1 year after their hospital stay $(13.5 \%$ in the smoking cessation programme group $v 9.2 \%$ in the control group). Incremental cost of the intervention was US $\$ 3680$ per incremental discounted life year saved. ${ }^{30}$ However, only $52 \%$ of participants provided samples for biochemical confirmation of abstinence. Because of this low rate, it is possible that some participants misreported their smoking status because of a social desirability factor. However, the authors used sensitivity analysis and found that even when the cessation rate was varied from $8.0 \%$ to $0.6 \%$, the intervention was still cost effective, with an incremental cost per incremental discounted life year saved of US $\$ 1978$ to $\$ 26373$.

Will the results help me in caring for patients? The applicability or generalisability of the results to your own setting needs to be considered. In an economic evaluation, the applicability of both the costs and effectiveness are assessed.

\section{DO THE COSTS IN THE REPORT APPLY IN MY OWN} SETTING?

Costs may vary because of local prices and different practice patterns. The sensitivity analysis should cover a range of costs that may account for such differences.
Table 4 Summary of an economic analysis on central line catheters and catheter related blood stream infection (CRBSI)

\begin{tabular}{ll} 
Feature & Study by Veenstra et al, 1999 \\
Overall study design & $\begin{array}{l}\text { Cost effectiveness analysis using a decision } \\
\text { analytic model }\end{array}$ \\
\hline Perspective of analysis & Healthcare payer \\
\hline Alternatives compared & $\begin{array}{l}\text { Standard or antiseptic impregnated } \\
\text { multilumen central venous catheters }\end{array}$ \\
\hline Effect measures & Incidence of CRBSI, death \\
\hline $\begin{array}{l}\text { Source of effectiveness } \\
\text { data }\end{array}$ & $\begin{array}{l}\text { Randomised controlled trials, meta-analysis, } \\
\text { case control studies }\end{array}$ \\
\hline $\begin{array}{l}\text { Source of quality of life } \\
\text { (utility) weights }\end{array}$ & N/A \\
\hline Source of cost data & $\begin{array}{l}\text { University of Washington Medical Center and } \\
\text { the literature }\end{array}$ \\
\hline Discounting & $\begin{array}{l}\text { Direct medical costs - University of } \\
\text { Washington Medical Center and the literature }\end{array}$ \\
\hline Addressing uncertainty & N/A \\
\hline $\begin{array}{l}\text { Multivariate sensitivity analyses with varying } \\
\text { estimates of direct medical costs, incidence } \\
\text { of CRBSI, and death attributable to CRBSI or } \\
\text { hypersensitivity reaction }\end{array}$ \\
$\begin{array}{l}\text { Univariate sensitivity analyses for incremental } \\
\text { costs: cost of CRBSI, relative risk of CRBSI, } \\
\text { incidence of CRBSI, and additional catheter } \\
\text { cost } \\
\text { Univariate sensitivity analyses for incremental } \\
\text { incidence of death: relative risk of CRBSI, } \\
\text { incidence of CRBSI, probability of death } \\
\text { attributable to CRBSI, and probability of } \\
\text { hypersensitivity }\end{array}$ \\
\hline
\end{tabular}

WILL THE INTERVENTION (OR NEW MODEL OF CARE) BE EFFECTIVE IN MY SETTING?

As always, you need to consider how your patients are similar to or different from those in the study. You also need to assess your patients' preferences for the outcomes and utilities used in the analysis.

\section{The search}

The interdisciplinary team charged with reviewing the literature on the new antiseptic impregnated catheter, searched Medline, the NHS Economic Evaluation Database, and the Health Technology Assessment Database (the latter 2 are part of the Cochrane Library) using the terms costs, central lines, and catheter related infection. The study thought best to answer the question is summarised in Table 4.

Veenstra et al assessed the cost effectiveness of short term use (2-10 d) of a standard multilumen central venous catheter compared with a catheter impregnated with chlorhexidine silver sulfadiazine for a hypothetical cohort of patients at high risk for catheter related infections. ${ }^{31}$ The economic evaluation method chosen, CEA, was appropriate for the question. The 2 alternative interventions were well defined and appropriate costs for each of the alternatives were considered in the analysis. Direct medical costs were measured in 1998 dollars and included costs related to incremental length of stay in the ICU and ward for management of catheter related bloodstream infections, hypersensitivity reactions, and locally infected catheter insertion sites.

The probabilities of clinical events were well documented. Probabilities for catheter related bloodstream infections and catheter colonisation were based on summary risk ratios calculated from a meta-analysis of 13 RCTs that compared outcomes for antiseptic impregnated catheters with standard central venous catheters. This meta-analysis included results from clinical trials in which most patients were at high risk (such as patients in ICUs or with immunosuppression). Probability of death attributable to catheter related bloodstream infections was based on reports in the literature. The authors found no 
reported cases of hypersensitivity to chlorhexidine silver sulfadiazine impregnated central venous catheters in the US, so they used rates from Japan. The analysis showed that antiseptic impregnated central venous catheters had greater efficacy and lower costs than standard catheters. These results remained consistent through an appropriate series of multivariate and univariate sensitivity analyses.

Although this study does not allow us to answer our first question about the total population of hospital patients requiring catheters, it does inform clinical decision making related to patients at high risk of catheter related infection. We have learned through appraisal of a high quality study that antiseptic impregnated central venous catheters are cost effective in high risk patients. Based on this economic evidence, the interdisciplinary team recommends use of the new catheters in their ICUs but not throughout the hospital until further studies are done.

PATRICIA W STONE, RN, PhD SUZANNE BAKKEN, RN, DNSc, FAAN Columbia University New York, New York, USA

CHRISTINE R CURRAN, RN, PhD, CNA The Ohio State University and Medical Center Columbus, Ohio, USA

PATRICIA H WALKER, RN, PhD, FAAN Graduate School of Nursing Uniformed Services University of the Health Sciences Bethesda, Maryland, USA
1 Eisenberg JM. JAMA 1989;262:2879-86.

2 Elixhauser A, Halpern M, Schmier J, et al. Med Care 1998;36:MS1-9, MS18-147.

3 Gerard K, Smoker I, Seymour J. Health Policy 1999;46:217-38.

4 Neumann PJ, Stone PW, Chapman RH, et al. Ann Intern Med 2000:132.964, 72

5 Guyatt G, Drummond R, editors. Users' guides to the medical literature. A manual for evidence-based practice. Chicago: AMA Press, 2002.

Neuhauser D, Lweicki AM. N Engl J Med 1975:293:226-8.

6 Neuhauser D, Lweicki AM. N Engl J Med 1975;293:

8 French MT, Sacks S, De Leon G, et al. Eval Health Prof 1999;22:60-85.

9 Bissinger RL, Allred CA, Arford PH, et al. Nurs Econ 1997;15:92-9.

9 Bissinger RL, Allred CA, Arford PH, et al. Nurs Econ

11 Graham JD, Corso PS, Morris JM, et al. Annu Rev Public Health Graham JD, Corsc

12 Torrance GW, Feeney D. Int J Technol Assess Health Care 1989;5:559-75.

13 Boyle MH, Torrance GW, Sinclair JC, et al. N Engl J Med 1983;308:1330-7.

14 Pauly MV. In Sloan F, editor. Valuing health care: costs, benefits, and effectiveness of pharmaceuticals and other medical technologies. Cambridge: Cambridge University Press, 1995:99-124.

15 Cherin DA, Huba GJ, Brief DE, et al. Home Health Care Serv Q 1998;17:5572.

16 Stone PW. Appl Nurs Res 2001;14:110-2.

17 Stone PW. Appl Nurs Res 2001;14:54-5.

18 Stone PW, Chapman RH, Sandberg EA, et al. Int J Technol Assess Health Care 2000;16:111-24.

19 Hornberger J, Lenert LA. Med Care 1996;34:DS23-33.

20 Bosch JL, Hammitt JK, Weinstein MC, et al. Med Decis Making 1998;18:381-90.

21 Patrick DL, Starks HE, Cain KC, et al. Med Decis Making 1994;14:9-18.

22 Lohr KN, Aaronson NK, Alonso J, et al. Clin Ther 1996;18:979-92.

23 Bell CM, Chapman RH, Stone PW, et al. Med Decis Making 2001:21:288-94.

24 Badia X, Diaz-Prieto A, Rue M, et al. Intensive Care Med 1996:22:1379-84.

25 Fryback DG, Dasbach EJ Klein R, al Med Decis Making 1993:13:89-102.

26 Stone PW. Image J Nurs Sch 1998;30:229-34.

26 Stone PW. Image J Nurs Sch 1998;30:229-34.

28 Gerard K, Mooney G. Health Econ 1993;2:59-64. 28 Gerard K, Mooney G. Health Econ 1993;2:59-64.
2000;20:451-67. Stone PW, Sandberg EA, et al. Med Decis Making

30 Meenan RT, Stevens VJ, Hornbrook MC, et al. Med Care 1998;36:670-8.

31 Veenstra DL, Saint S, Sullivan SD. JAMA 1999;282:554-60. 
In 2001, the Honor Society of Nursing, Sigma Theta Tau International and Nursing Spectrum sponsored an "Innovations in Clinical Excellence" contest to recognise exemplars of evidence-based nursing practice. The following are 2 of the winning entries.

\section{Evidence-based development of a hospital based heart failure centre}

Heart failure (HF) is a syndrome of shortness of breath and fatigue. It occurs when forward flow of blood out of the heart is impeded. This is the only cardiovascular condition that continues to increase in prevalence and incidence. It is a major healthcare problem, not only for the patient, but also for significant others and the community at large. The condition accounts for approximately 12-15 million office visits and 6.5 million hospital days annually in the United States. One third of those discharged from the hospital are readmitted within 90 days because of recurrence of symptoms. The cost of HF patient care is approximately $\$ 38.1$ billion annually, draining limited resources of patients, treatment facilities, and society. ${ }^{1-3}$

\section{Type of evidence used}

To effectively deal with the problem of high HF admission rates and with the associated high number of days of hospitalisation, costs per case, and recidivism, ${ }^{14-7}$ Jersey Shore Medical Center staff used a multidisciplinary approach in developing an HF centre. Evidence was retrieved from medical, nursing, and allied health literature. Existing HF centres were observed as well.

\section{Method used to obtain and review evidence}

The project manager and a physician who strongly supported the development of an HF centre visited several model HF centres in the United States. They spoke with experts in the field and gathered many ideas. Literature was reviewed to determine a "best fit" design for the planned facility. ${ }^{4-5} 8-12$ A decision was made to have a physician directed, advanced practice nurse run centre to best serve the needs of the physicians with whom we work, and the community we treat. A decision was also made to hire an experienced advanced practice nurse (APN) with a broad cardiology background. ${ }^{13}$ The APN would run the HF programme based on guidelines developed by the project manager and medical director.

\section{Planned strategies}

The HF centre was developed with goals mutually beneficial to patients and the facility. The outpatient portion of the programme was designed to help patients retain optimal heart health outside of the hospital. APNs would run the centre, providing collaborative care and aggressive education to referred patients as indicated in the literature. ${ }^{11}{ }^{13}$ Patients would be seen on site for physical assessments and treatment as indicated in the literature. ${ }^{314-19}$ Aggressive multidisciplinary education would be offered, using the resources of the hospital to provide patients with optimal care as indicated in the literature..$^{20-23}$ Patients would be routinely telemonitored to assess level of $\mathrm{HF}$ compensation. $^{24}$

Decompensation, when diagnosed early, could be easily remedied. If patients required readmission to the hospital, they would likely be less acutely ill and remain hospitalised for a shorter time, decreasing length of stay as indicated by Bennett $e t$ $a l^{25}$ and by Rich et $a l .{ }^{26}$ The advanced practice staff would also see all hospitalised patients with HF. They were to assess patients' needs and expedite meeting those needs. The HF staff would also educate patients and provide literature for them to take home. Questions and concerns would be addressed. Diagnostic departments were to be called to ensure timely scheduling of tests. APNs were to collaborate with physicians to optimise patient care and gain referrals to the outpatient centre. Dietary consultation would be routinely requested. Case managers and social workers were given preliminary advice about potential patient discharges, so that discharge needs could be anticipated in advance of actual discharge. ${ }^{82} 27-31$

\section{How the strategies were implemented}

The APN was hired. Space was set up for the outpatient centre near a telemetry unit, within easy access of the front door. 3 rooms were provided for the HF centre: an office, an examination room, and a treatment room. Office equipment and supplies were ordered including a video system and patient literature. Hands-on teaching tools and compliance aids were ordered using funds from the Heart Failure Center Foundation. A semiprivate room is used as a treatment room. In this room, patients can rest in bed while they receive diuretics or intermittent inotropic infusion therapy. ${ }^{32}$ These patients receive care from the telemetry unit nursing staff.

Free valet parking was set up for patients. Necessary forms were designed and a registrar is on site. Many meetings were held with ancillary departments to streamline every process including medical record charting, supply distribution, consultations, information technology, reporting, and finance. Multidisciplinary meetings were held with managers from nutrition, cardiac rehabilitation, clinical pharmacy, case management, and social services departments to set up support services for outpatients. Decisions were made about how best to provide excellent customer service. Meetings were held monthly to discuss progress concerning the programme. Surveys were obtained or developed to assess patients' functional status, quality of life, and satisfaction. Such tools ${ }^{33-37}$ are administered upon enrollment in the programme, and regularly thereafter, to assess patient progress.

For the inpatient portion of the programme, patient handouts were developed. Information technology staff assisted with implementing computerised standing orders for HF patients on the coronary care, telemetry, and medical units. Additional orders were implemented including routinely prescribed medications for HF patients. Consultation guidelines were instituted for referrals to the HF centre, and nursing staff, clerical staff, physicians, and office managers attended inservice education programmes about expectations. HF guidelines were also distributed to the medical staff as recommended in the literature. $^{315}$ 


\section{Method of evaluation}

Evaluation of the inpatient portion of the programme included variables such as length of stay, cost per case, and use of $\mathrm{HF}$ medications such as angiotensin converting enzyme (ACE) inhibitors, angiotensin receptor blockers, hydralazine and nitrate combinations, and $\beta$-blockers. These variables were compared monthly and quarterly. Audits of clinical pathway variables were performed to assess effectiveness of hospitalisation. Areas of deficiency were the focus of improvement strategies through our multidisciplinary clinical service team. The HF centre's staff developed the first physician report card for our healthcare system. After a blinded audit, cardiologist variables were presented to the cardiology section, so that practice issues could be assessed, compared, and improved. Post-hospitalisation telephone surveys were conducted to assess patient satisfaction.

Evaluation for the outpatient programme included assessing quality of life and functional status (Minnesota Living with Heart Failure Questionnaire and SF 12) and physical endurance (Six-Minute Walk ${ }^{33}$ ). These were measured upon enrollment and at regular intervals. Heart failure admission rates for our enrolled patients were compared to HF readmissions for all non-enrolled patients at 30,60, and 90 days to show the benefit of our outpatient programme. Outpatient satisfaction surveys are mailed to patients quarterly.

\section{Outcomes/results}

Hospital length of stay decreased from 8.4 to 6.5 days within 6 months. Associated cost savings to the facility were over $\$ 360000$. The first full year of operation led to continued decreases in length of stay and an additional \$255000 saved. Recidivism decreased from $33 \%$ to $13 \%$ or less

Physician report cards yielded useful information that led to awareness of prescribing practices and overall improved length of stay, cost per case, and adherence to standard HF medications. Audits of clinical pathway variables showed several areas for improvement. Resultant changes were made in areas such as (a) timely performance of 2-dimensional echocardiograms; (b) timely documentation of findings in patients' records; and (c) more accurate medical record charting for patients with renal diseases, without heart disease. These changes led to more accurate diagnostic related group (DRG) coding with reimbursement ramifications. Inpatient satisfaction surveys indicated good recall about the HF centre staff visits and the education provided.

Quality of life evaluations for outpatients showed a 33\% improvement in functional status and physical endurance, and a $25 \%$ improvement in quality of life during the first 6 months of participation with the centre. Use of ACE inhibitors was found to be better for outpatients at the centre than for inpatients$89 \%$ v 50\%, respectively. Patient satisfaction with the programme remains high. Patients and family members have written letters of praise and support. Some have even contributed to the hospital's Heart Failure Center Foundation.

\section{Lessons Learnt}

Development of the HF centre was challenging. Several changes were made in the nursing care process for patients receiving intravenous inotropic infusions and diuretic therapy. Physician report cards were amended for enhanced accuracy. The clinical pathway has evolved into a process, rather than a form to be completed. Physician satisfaction surveys are currently being developed.

This hospital based, APN administered heart failure centre is an effective way to decrease length of stay and associated financial burdens to patients, our facility, and ultimately, to society.
Outpatients enrolled in this programme greatly benefit from a decrease in recidivism and from improved functional status, physical endurance, and quality of life.

MARYANNE CROWTHER, RN, MSN, APNC, CCRN ANN MAROULIS, RN, MSN, APNC, CCRN

NANCY SHAFER-WINTER, RN, MSN, APNC, CCRN, CNA, CPHQ RICHARD HADER, RN, PhD, CHE, CNA, CPHQ Jersey Shore Medical Center Neptune, New Jersey, USA

Reprinted with permission of the Honor Society of Nursing, Sigma Theta Tau International from Crowther M, Maroulis A, Shafer-Winter, et al. Evidence-based development of a hospitalbased heart failure center. Online J Knowl Synth Nurs 2002;9:5C

1 American Health Consultants. Congestive heart failure: the disease state management resource. Vol 2. Atlanta: American Health Consultants, 1998.

2 Hunt SA, Baker DW, Chin MH, et al. ACC/AHA guidelines for the evaluation and management of chronic heart failure in the adult:executive summary: a report of the American College of Cardiology/American Heart Task Force on Practice Guidelines. J Am Coll Cardiol 2001;38:2101-13. http.//www.acc.org/ clinical/guidelines/failure/exec_sum/hf_index.htm

3 Consensus recommendations for the management of chronic heart failure. On behalf of the membership of the Advisory Council to Improve Outcomes Nationwide in Heart Failure. Am J Cardiol 1999:83:1A-38A.

4 Brass-Mynderse NJ. Disease management for chronic congestive heart failure.J Cardiovasc Nurs 1996;11:54-62.

5 Cardiology Preeminence Roundtable. Beyond four walls: cost-effective management of chromic congestive heart failure. Washington, DC: Advisory Board Company, 1994

6 Knox D, Mischke L. Implementing a congestive heart failure disease management program to decrease length of stay and cost. J Cardiovasc Nurs 1999;14:55-74.

7 Wells N, Johnson R, Salyer S. Interdisciplinary collaboration. Clin Nurse Spec 1998;12:161-8.

8 Brubakken KM, Janssen WR, Ruppel DL. CNS roles in implementation of a differentiated case management model. Clin Nurse Spec 1994;8:69-73.

9 Chapman DB, Torpy J. Development of a heart failure center: a medical center and cardiology practice join forces to improve care and reduce costs. Am J Manag Care 1997;3:431-7.

10 Fonarow GC, Stevenson LW, Walden JA, et al. Impact of a comprehensive heart failure management program on hospital readmission and functional status of patients with advanced heart failure. J Am Coll Cardiol 1997;30:725-32.

11 McCormick SA. Advanced practice nursing for congestive heart failure. Crit Care Nurs Q 1999;21:1-8.

12 Wilkes RM, Dukes KR, Feagles LL, et al. Kaiser Permanente's approach to congestive heart failure in south San Francisco. Journal of Clinical Outcomes Management 1999;6:37-40.

13 Paul S. Implementing an outpatient congestive heart failure clinic: the nurse practitioner role. Heart Lung 1997;26:486-91.

14 Effects of enalapril on mortality in severe congestive heart failure. Results of the Cooperative North Scandinavian Enalapril Survival Study of the Cooperative North Scandinavian Enalapril Survival Study
(CONSENSUS). The CONSENSUS Trial Study Group. $N$ Engl J Med 1987:316:1499-35.

15 Heart Failure Society of America (HFSA) practice guidelines. HFSA guidelines for management of patients with heart failure caused by left guidelines for management of patients with heart failure caused by left
ventricular systolic dysfunction-pharmacological approaches. J Card Fail ventricular systo

16 Hosenpud JD, Greenberg BH, editors. Congestive heart failure: pathophysiology, diagnosis, and comprehensive approach to management. New York: pringer-Verlag, 1994.

17 Kramer BK, Schweda F, Riegger GA. Diuretic treatment and diuretic resistance in heart failure. Am J Med 1999;106:90-6.

18 Effect of enalapril on survival in patients with reduced left ventricular ejection fractions and congestive heart failure. The SOLVD Investigators. $N$ Engl J Med 1991;325:293-302.

19 Stevenson LW, Massie BM, Francis GS. Optimizing therapy for complex or refractory heart failure: a management algorithm. Am Heart $J$ 1998;135:S293-309.

20 Allison M, Keller C. Physical activity in the elderly: benefits and intervention strategies. Nurse Pract 1997;22:53-4, 56, 58 passim.

21 Kostis JB, Rosen RC, Cosgrove NM, et al. Nonpharmacologic therapy improves functional and emotional status in congestive heart failure. Chest 1994;106:996-1001.

22 Luniewski M, Reigle J, White B. Card sort: an assessment tool for the educational needs of patients with heart failure. Am J Crit Care 1999;8:297-302. 3 Simon-Weinstein M. Cardiac rehabilitation: nonpharmacologic treatment for congestive heart failure. J Am Acad Nurse Pract 1999;11:293-6.

24 Johnson MJ, Frank DI. Effectiveness of a telephone intervention in reducing anxiety of families of patients in an intensive care unit. Appl Nurs Res 1995;8:42-3.

25 Bennett SJ, Huster GA, Baker SL, et al. Characterization of the precipitants of hospitalization for heart failure decompensation. Am J Crit Care 1998;7:168-74.

26 Rich MW, Vinson JM, Sperry JC, et al. Prevention of readmission in elderly patients with congestive heart failure: results of a prospective randomized pilot study. J Gen Intern Med 1993;8:585-90.

27 Ethridge P, Lamb GS. Professional nursing case management improves quality, access and costs. Nurs Manage 1989;20:30-5.

28 Haddock KS. Collaborative discharge planning: nursing and social services. Clin Nurse Spec 1994;8:248-52, 288.

29 Krumholz HM, Butler J, Miller J, et al. Prognostic importance of emotional support for elderly patients hospitalized with heart failure. Circulation
1998;97:958-64.

Lynn-McHale DJ, Fitzpatrick ER, Shaffer RB. Case management: develop-
ment of a model. Clin Nurse Spec 1993;7:299-307. 
31 Philbin EF, Rocco TA, Lindenmuth NW, et al. The results of a randomized trial of a quality improvement intervention in the care of patients with 32 Patel MB, Kaplan IV, Patni RN, et al. Sustained improvement in Patel MB, Kaplan IV, Patni RN, et al. Sustained improvement in flow-mediated vasodilation after short-term administration of dobutamine 33 in patients with severe congestive heart failure. Circulation 1999;99:60-4. Lucas C, Stevenson LW, Johnson W, et al. The 6-min walk and peak oxygen Heart J 1999;138:618-24.
34 Bittner V. Determining prognosis in congestive heart failure: role of the 6-minute walk test. Am Heart J 1999;138:593-6.

5 Dracup K Walden JA Stevenson LW, et al Quality of life in patients with advanced heart failure. J Heart Lung Transplant 1992;11:273-9.

36 Hawthorne MH, Hixon ME. Functional status, mood disturbance, and Hawthorne MH, Hixon ME. Functional status, mood disturbance, and quality of life in patients with heart failure. Prog Cardiovasc Nurs 1994;9:22-32.

Woo MA, Moser DK, Stevenson LW, et al. Six minute walk test and heart rate variability: lack of as

\section{Using a FOCUS-PDCA quality improvement model for applying the severe traumatic brain injury guidelines to practice: process and outcomes}

Trauma teams strive to provide care based on best practice. Exploring the clinical outcomes of patients sustaining severe traumatic brain injury (TBI) at our trauma centre from 1994-97 we found that the outcomes were marginal at best: $43 \%$ of our patients expired and 30\% suffered severe disability. These results were consistent with those of some studies on TBI published in the 1980s. Researchers in the past decade have used new technology for monitoring the effects of secondary brain injury and examined the effects of various treatment modalities on the outcomes of patients with TBI. In 1995, the American Association of Neurological Surgeons (AANS) evidence-based clinical guidelines for managing severe TBI were published. ${ }^{1}$ The guidelines recommended changes in the care of patients with TBI and challenged caregivers to evaluate their practices and examine the clinical outcomes of this high risk group.

Motivated by the new practice recommendations and the potential for greatly affecting patient outcomes, Mission Hospital Regional Medical Center's (MHRMC) multidisciplinary neurotrauma team convened in 1997 to begin performance improvement. Current practice was examined and new hospital based clinical guidelines were developed. Numerous changes were recommended as the team dismantled current practice patterns and constructed new care priorities. The result was a series of algorithms with established outcomes at every phase of the patient's hospital course. Four years after integrating the changes in practice, the team evaluated prospectively collected data to determine outcomes for patients with severe TBI. Current outcomes (2001 data) indicated that $72.8 \%$ of patients had a good outcome (no disability to moderate disability), $13.6 \%$ had severe disability to persistent vegetative state, and $13.6 \%$ died. We will present a FOCUS-PDCA performance improvement approach to show the processes used to apply national scientific guidelines to the clinical setting. Statistical analysis using an ordinal regression model will show outcome data emphasising the positive aspects of applying evidence-based guidelines to practice.

\section{Summary of FOCUS-PDCA}

FOCUS is an acronym for the words find, organise, clarify, understand, and select. PDCA is an acronym for plan, do, act, and check results.

\section{FIND A PROCESS TO IMPROVE}

The trauma/neurosurgical physician and nursing leaders at MHRMC gathered in 1997 to facilitate the transition of research based scientific guidelines to clinical practice. The guidelines for managing severe head injury developed by the AANS challenged physicians and other health team members to examine current practice regarding severe TBI patients and to alter care practices, which had been viewed as the "gold standard" of care for years. Analysis of the TBI guidelines and related literature indicated recommendations to avoid hypoxia and hypotension; maintain a mean arterial pressure $<90 \mathrm{~mm}$ $\mathrm{Hg}$ and cerebral perfusion pressure $>70 \mathrm{~mm} \mathrm{Hg}$ using fluids and vasopressors; treat intracranial pressure (ICP) > $20 \mathrm{~mm} \mathrm{Hg}$; avoid hyperventilation to control ICP unless cerebral oxygenation measured; give boluses of mannitol intermittently and replace fluids to maintain euvolemia; use barbiturates for uncontrollable ICP; decrease stimulation in the environment; treat fever aggressively; use sedation or analgesia in continuous modes; and incorporate clinical pathways and algorithms concerning planned therapy including weaning procedures. ${ }^{1}$

\section{ORGANISE TO IMPROVE THE PROCESS}

The team leaders began by examining the current care processes for the population with TBI at MHRMC. They conducted a review of the literature and contacted a manufacturer of cerebral oxygenation $\left(\mathrm{SjO}_{2}\right)$ catheters concerning product availability. A decision was made by the leaders to form a multidisciplinary team to examine current practice, analyse the published TBI guidelines and research, and develop new treatment plans.

\section{CLARIFY THE ISSUE}

The neuro clinical nurse specialist (CNS) conducted a retrospective chart review of the previous 3.5 years. Patients included in the study were those with a closed head injury and (a) Glasgow Coma Score (GCS) from 3-8, (b) abnormal computed tomography (CT) scan of the brain, (c) age $>8$ years, and (d) ICP monitoring. Excluded from the study results were patients with penetrating head injury; patients who died or were pronounced brain dead within 24 hours of admission; patients with a GCS 3-8 because of alcohol, seizures, or systemic injury; and patients with absence of head injury as determined by CT or clinical exam. In all, 1937 trauma records were reviewed (January 1994 to June 1997). Almost half of the patients had sustained some form of head injury but only 37 met inclusion criteria. Results of the outcome study were that $27 \%$ had an outcome of zero to moderate disability; $30 \%$ had severe disability or persistent vegetative state (PVS); and 43\% died.

After the chart audit, a multidisciplinary task force was established consisting of trauma surgeons, neurosurgeons, anaesthesiologists, intensivists, rehabilitation personnel, critical care nurses, respiratory therapists, and pharmacists. Before the meeting, all members received a copy of the TBI guidelines and supporting research articles. The neuro CNS facilitated 2 meetings to compare the guidelines to current practice and establish clinical guidelines for use at the hospital. 
UNDERSTAND THE SOURCES OF VARIATION AND SELECT THE PROCESS TO IMPROVE

The team discovered that current practice deviated from the published guidelines in several areas including blood pressure (BP) and fluid management; use of hyperventilation to treat increased ICP; use of medications to decrease cerebral oxygen demand, enhance BP, and decrease ICP; temperature management; and use of technology such as $\mathrm{SjO}_{2}$ catheters to monitor cerebral oxygenation. Recommendations from members of the team were to discontinue the old treatment processes and implement a new care process incorporating the AANS TBI guidelines and recommendations in the literature that were focused on decreasing ICP, maximising BP, and optimising cerebral oxygenation. The team integrated information on manipulation of cerebral oxygenation so as to maintain normal oxygen levels. ${ }^{2}$

\section{PLAN, DO, AND ACT-JUNE 1997}

Changes were recommended as the team changed practice patterns and implemented new care priorities. Every aspect of caring for patients with severe TBI from admission in the emergency department (ED), through the operative and intensive care unit (ICU) phase, to rehabilitation was examined. The result was to develop a series of algorithms with established outcomes at every phase of a patient's hospital course. Input from every member of the multidisciplinary team was sought for the care process. $\mathrm{SjO}_{2}$ catheters were stocked in the hospital, a procedure was developed, and the staff was educated. The team developed a TBI documentation form, algorithms for the ICU team, and clinical guidelines addressing the needs of adults and children. In addition, staff members in the paediatric and adult ICUs, ED, and operating room (OR) were educated about the new process. The first patient to be cared for using the new guidelines was admitted in June 1997. This change in practice required close supervision and clinical support of team members by the neuro CNS who provided clinical support for all shifts.

\section{CHECK RESULTS-JUNE 1998}

Analysis of care processes, data, and outcomes was integral to maintain consistency of care and coordination of services. Data were collected prospectively by the neuro CNS. Analysing outcomes for 18 patients using the new guidelines indicated that $61 \%$ had a good outcome with zero to moderate disability; $11 \%$ had severe disability or PVS; and 27\% died. Feedback from members of the team included several concerns regarding the management of these patients.

Team members were concerned about variations in intubation procedures; variation in maintaining minimum BP levels for the ED and OR phases of care; variation in timing the placement of $\mathrm{SjO}_{2}$ catheters; variations in intra-operative management; and instances of increased incidence of pneumonia, poor renal perfusion, nutritional problems, and acute withdrawal symptoms because of sudden removal of analgesics.

\section{ACT-August 1998}

The neuro CNS reconvened the multidisciplinary team and reviewed the results of the first year. The key issues identified above were divided into phases of care and changes in practice were recommended. New clinical algorithms were developed. The team developed (a) protocols for rapid sequence intubations, narcotic withdrawal, and vasopressor support; (b) goals such as BP, ICP, and cerebral oxygenation levels for each phase of care; (c) nutritional management goals, with emphasis on post-pyloric feedings, which would provide nutrition into the small intestine instead of into the stomach; (d) interventions for aggressive pulmonary management; and (e) ways to use nursing research about management of environmental stimulation and family presence. We implemented changes in practice after approval by committees and staff education.

\section{CHECK AGAIN-FEBRUARY 2000}

Outcome data were evaluated once again. 56 patients were cared for since the change in practice in June 1997 and dramatic improvement in outcomes was noted: $69 \%$ had a good outcome of zero to moderate disability, 14\% had severe disability or PVS, and $16 \%$ died. We sought the assistance of an independent statistician to analyse the data. Patients in Group $1(n=37)$ were those treated before the TBI guidelines were implemented and patients in Group $2(n=56)$ were those treated after TBI guidelines were implemented. A comparison of descriptive statistics using a student $t$ test revealed no significant difference between the 2 groups concerning the variables of age, injury severity score, GCS on admission, number of days receiving ICP monitoring, number of days on mechanical ventilation, ICU length of stay (LOS), and hospital LOS. Statistically significant differences were noted between the 2 groups concerning hospital charges (\$197 128 average for patients in Group 1 and \$293 065 average for patients in Group 2). Using an ordinal regression model, the odds for significant variables were examined and adjusted for the effect of all other variables in the model. Results of the ordinal regression model were (a) patients in Group 2 had odds of a good outcome relative to odds of a poor outcome or death 9 times higher compared with patients in Group $1(\mathrm{p}=0.005)$; (b) patients with a GCS $>8$ at the time of admission had odds of a good outcome 6.58 times higher compared with the patients admitted with a GCS $<8(\mathrm{p}=0.003)$; and (c) odds of a good outcome decreased by a factor of 0.92 for each 1 year increase in patients' age starting at age $9(\mathrm{p}=0.0005)$.

Team members believe the change in outcomes of the severe TBI population was because of an aggressive standardised approach to managing multiple parameters and to the integration of advanced technology related to brain oxygenation. By integrating team interventions into one protocol, nurses, physicians, respiratory therapists, and members of other disciplines coordinated their interventions and understood the effect on patients. Using a standardised approach has been reported to be successful in other centres. ${ }^{3-5}$

\section{ACT AGAIN-200O}

The team recognised the need to encourage more family involvement in the care of patients with severe TBI. The TBI Task Force 2000 met and included hospital staff from all units, 4 former patients, and several family members. Using a qualitative approach, input from all members was gathered and 4 teams established new care practices involving: (a) patients emerging from coma; (b) structure of the physical environment in all units; (c) consistency and continuity of care; and (d) patient and family education and support.

Families are educated about the ICU environment and encouraged to be present at their ICU patient's bedside as much as possible. Therapeutic touch by family members is encouraged and supported. Members of the nursing and rehabilitation teams from units where the patient will be cared for meet the family while the patient is in the ICU. Families receive relevant education as patients move through each phase of care. Care practices and outcomes are continually monitored.

Data collected about patients $(n=81)$ at the end of fiscal year 2000 showed that $72.8 \%$ had good outcomes of zero to moderate disability, $13.6 \%$ had severe disability or PVS, and $13.6 \%$ died. These outcomes indicated to the team that the changes in practice and intense cooperation resulted in a difference in their 
patients. Each team member's collaboration and respect for others were evident in actions and words. This multidisciplinary team evolved and became synergistic with each patient and family. This synergy has enabled us to affect outcomes of severely brain injured patients at MHRMC.

\section{MARY KAY BADER, RN, MSN, CCRN, CNRN \\ SYLVAIN PALMER, MD, FACS \\ CONNIE STALCUP, RN, MSN \\ THOMAS SHAVER, MD, FACS \\ Mission Hospital Regional Medical Center \\ Mission Viejo, California, USA} Reprinted with permission of the Honor Society of Nursing, Sigma Theta Tau International
from Bader MK, Palmer S, Stalcup C, et al. Using a FOCUS-PDCA quality improvement model for applying the severe traumatic brain injury guidelines to practice: process and outcomes. Online J Knowl Synth Nurs 2002;9:4C.

1 Bullock R, Chestnut R, Clifton G, et al. Guidelines for the management of severe brain injury. New York: Brain Trauma Foundation/American Association of Neurological Surgeons, 2000 .

2 Robertson CS, Valadka AB, Hannay HJ. Prevention of secondary ischemic insults after severe head injury. Crit Care Med 1999;27:2086-95.

3 Baethmann A, Lehr D, Wirth A. Prospective analysis of patient management in severe head injury. Acta Neurochir Suppl (Wien)

4 McKinley BA, Parmley CL, Tonneson AS. Standardized management of intracranial pressure: a preliminary clinical trial. J Trauma 1999;46:271-9. 5 Simons R, Eliopoulos V, Laflamme D, et al. Impact on process of trauma care delivery one year after the introduction of a trauma program in a provincial trauma center. J Trauma 1999;46:811-6.

\section{Acknowledgements}

A s our sixth year of publication begins, we would like to thank the many people who have contributed their time, expertise, - and enthusiasm to Evidence-Based Nursing over the past year.

ur Associate Editors (listed on the inside front cover), who helped us to select articles that are clinically important and relevant to practising nurses, as well as methodologically sound; reviewed and edited numerous structured abstracts and commentaries; and so much more.

ur panel of advisers on qualitative research, who helped us to select qualitative research papers for abstraction:

Wally Barr, Liverpool, UK

Caroline Carlisle, Liverpool, UK

Chantal Caron, Sherbrooke, Quebec, Canada

Marlene Z Cohen, Houston, Texas, USA

Heather MacDonald, Fredericton, New Brunswick, Canada

Jenny Ploeg, Hamilton, Ontario, Canada
Rita Schreiber, Victoria, British Columbia, Canada

Cynthia Russell, Memphis, Tennessee, USA

Carl Thompson, York, UK

Sally Thorne, British Columbia, Canada

Carol Tishelman, Stockholm, Sweden

The individuals who helped us in the selection of quantitative studies that are clinically important and relevant to practising nurses:

Brenda Morgan, London, Ontario, Canada

Jennifer Skelly, Hamilton, Ontario, Canada

Brian Hutchison and Trevor Sheldon, who provided thoughtful methodological advice about selected studies.

The people who served as peer reviewers for the EBN Notebook and Implementation Forum, for their thoughtful and timely feedback:

Kate Flemming, York, UK

Pat Mandy, Hamilton, Ontario, Canada

Dorothy McCaughan, York, UK

David Torgerson, York, UK

Jane Underwood, Hamilton, Ontario, Canada

Carl Thompson, York, UK

\section{Correction}

In the October 2002 issue, the authors of the EBN users' guide (Evaluation of studies of health economics) were listed incorrectly. They should have been listed as follows:

Patricia W Stone, RN, PhD

Columbia University, New York, New York, USA

Christine R Curran, RN, PhD, CNA

The Ohio State University and Medical Center, Columbus, Ohio, USA

Suzanne Bakken, RN, DNSc, FAAN

Columbia University, New York, New York, USA

Patricia H Walker, RN, PhD, FAAN

Graduate School of Nursing, Uniformed Services University of the Health Sciences, Bethesda, Maryland, USA 